\title{
Pengembangan Media Pembelajaran Ekonomi Berbasis Komputer Model Drills Untuk Siswa Kelas X SMA Islam Bina Insan
}

\author{
Sapka Mawarzani ${ }^{1}$ Refreandi Haeri ${ }^{2}$ \\ ${ }^{1,2}$ Pendidikan Ekonomi Koperasi, Universitas Qamarul Huda Badaruddin Bagu \\ Email : ahmadrazkany@gmail.com
}

Received: 27 Nopember, 2020; Accepted: 23 Desember 2020; Published: 25 Desember, 2020

\begin{abstract}
Abstrak
Media merupakan segala sesuatu yang dapat digunakan untuk menyalurkan pesan dari pengirim ke penerima sehingga dapat merangsang pikiran, perasaan, perhatian, dan minat serta perhatian siswa sedemikian rupa sehingga proses belajar terjadi, media dalam dunia pendidikan digunakan dalam rangka memperbaiki kualitas pembelajaran salah satunya media pembelajaran berbasis komputer. Menjadi tugas dan tanggung jawab guru dalam memanfaatkan media pembelajaran yang sesuai dengan kebutuhan dan minat belajar siswa, dan salah satu media yang sesuai dengan minat belajar siswa yaitu media pembelajaran berbasis komputer model drills. Tujuan penelitian dan pengembangan ini adalah: 1) menghasilkan Media Pembelajaran ekonomi berbasis komputer model Drills yang akan digunakan untuk tahun-tahun berikutnya pada siswa kelas X SMA Islam Bina Insan 2) mengetahui kelayakan Media Pembelajaran ekonomi berbasis komputer yang dikembangkan menurut penilaian ahli Media dan ahli materi, 3) mengetahui tanggapan validator ahli dan siswa terhadap bahan ajar ekonomi berbasis komputer model Drills yang telah dikembangkan, dan 4) mengetahui efektifitas Media pembelajaran ekonomi berbasis komputer model drills yang dikembangkan. Jenis penelitian ini adalah penelitian pengembangan dengan model Borg and Gall yang telah dimodifikasi menjadi delapan langkah pengembangan. Langkah-langkah pengembangan meliputi: 1) potensi dan masalah, 2) pengumpulan data, 3) desain produk, 4) validasi desain, 5) revisi desain, 6) uji coba produk, 7) revisi produk, dan 8) produk akhir. Pengumpulan data dilakukan dengan angket dan tes. Target luaran dari penelitian ini adalah publikasi di jurnal nasional terakreditasi, luaran lainnya dapat berupa sebuah produk media pembelajaran berbasis komputer model drills.

Hasil penelitian menunjukkan bahwa, 1). Adanya produk berupa Media Pembelajaran ekonomi berbasis komputer model Drills Untuk SMA Islam Bina Insan. 2). Media pembelajaran ekonomi berbasis komputer model Drills ini layak digunakan, hal tersebut dapat dilihat dari hasil validasi ahli materi ekonomi sebesar $89,09 \%$ (layak), untuk ahli media sebesar 92,30\% (layak). 3). Respon guru dan siswa menunjukkan respon yang positif dilihat dari hasil uji coba lapangan yakni hasil angket respon guru sebesari $100 \%$ dan respon siswa sebesar 89,6\%. 4).Untuk hasil aktifitas belajar siswa sebesar 3,7 dengan demikian Media Pembelajaran ekonomi berbasis komputer model Driils ini efektif digunakan.
\end{abstract}

Kata Kunci : Media, Pembelajaran berbasis komputer model Drills, Pengembangan 


\begin{abstract}
Media is anything that can be used to transmit messages from sender to receiver so that it can stimulate thoughts, feelings, attention, and student interests in such a way that the learning process occurs, media in education is used to improve the quality of learning, one of which is based learning media. computer. It is the duty and responsibility of the teacher in utilizing learning media that is in accordance with the needs and interests of student learning, and one of the media that is in accordance with student learning interests, namely computer-based learning media drills model. The objectives of this research and development are: 1) to produce a Drills model of computer-based economic learning media which will be used for the following years in class X students of Bina Insan Islamic Senior High School 2) to determine the feasibility of computer-based economic learning media developed according to the assessment of media experts and experts material, 3) knowing the responses of expert validators and students to the Drills model of computer-based economics teaching materials that have been developed, and 4) knowing the effectiveness of the developed drills model of computer-based economic learning media. This type of research is development research with the Borg and Gall model which has been modified into eight development steps. Development steps include: 1) potentials and problems, 2) data collection, 3) product design, 4) design validation, 5) design revision, 6) product testing, 7) product revision, and 8) final product. Data collection was carried out by means of questionnaires and tests. The target output of this research is publication in accredited national journals, another output can be a computer-based learning media product model of drills.

The results showed that, 1). There is a product in the form of a computerbased economic learning media with the Drills model for Bina Insan Islamic Senior High School. 2). This Drills model of computer-based economic learning media is feasible to use, it can be seen from the validation results of economic material experts of $89.09 \%$ (feasible), for media experts it is $92.30 \%$ (feasible). 3). The teacher and student responses showed a positive response seen from the results of field trials, namely the results of the teacher's questionnaire response of $100 \%$ and student responses of $89.6 \%$. 4). For the results of student learning activities of 3.7, thus the Driils Model of computer-based economic learning media is effectively used.
\end{abstract}

Keywords: Development; Drills Model Of Computer Based Learning; Media.

\title{
PENDAHULUAN
}

Perkembangan peradaban semakin cepat terlebih saat ini memasuki apa yang disebut dengan revolusi industri gelombang keempat atau industry 4.0. Indonesia merupakan bagian dari masyarakat global yang kena imbas dari kemajuan peradaban tersebut dan sudah melebur disemua aspek kehidupan termasuk dalam dunia pendidikan, dimana arus perubahan teknologi memegang peranan penting dalam perkembangan pendidikan. Minat siswa dalam menggunakan teknologi 
seyogyanya dapat dijadikan cara dalam meningkatkan kualitas pendidikan, (Serin, 2011) mengatakan bahwa di antara para siswa sekolah dasar dan menengah, anak perempuan menggunakan komputer 5 jam seminggu untuk bermain sedangkan anak laki-laki menghabiskan 13 jam seminggu untuk hal yang sama. Pemilihan media pembelajaran yang tepat sangat berpengaruh terhadap motivasi dan hasil belajar siswa penekananya seorang guru harus mampu memilih media yang baik agar tujuan pembelajaran dapat tercapai dengan baik. media pembelajaran berbasis komputer merupakan bagian dari solusi yang tepat untuk memilih media pembelajaran yang baik hanya permasalahannya guru belum maksimal menggunakannya karena masih bingung media pembelajaran berbasis komputer seperti apa yang baik diterapkan, salah satu alternatif media pembelajaran berbasis komputer yang baik dan tepat digunakan adalah menggunakan media pembelajaran berbasis komputer model drills. Model drills merupakan suatu model dalam pembelajaran dengan jalan melatih siswa terhadap bahan pelajaran yang sudah diberikan. Model drills akan menanamkan kebiasaan tertentu pada siswa dalam bentuk latihan, karena dengan latihan yang secara terus menerus akan tertanam dan kemudian menjadi sebuah kebiasaan yang menyenangkan, selain itu juga dapat menambah kecepatan, kesempurnaan dalam melakukan sesuatu serta dapat pula dipakai sebagai suatu cara mengulangi bahan latihan yang disajikan.

Merujuk pada hasil observasi di SMA Islam Bina Insan, didapatkan guru mengajar masih menggunakan model konvensional, sesekali guru menggunakan media pembelajaran namun masih menggunakan media seadanya dengan memanfaatkan benda yang ada dan tidak menggunakan media berbasis komputer secara maksimal. Padahal untuk memaksimalkan pembelajaran agar mahasiswa berminat dan termotivasi dalam belajarnya di butuhkan media pembelajaran yang baik, seperti dijelaskan dalam penelitian (Dewi \& Nugroho, 2015) bahwa media pembelajaran dapat meningkatkan motivasi bahkan keterampilan memprediksi siswa. Oleh karena itu ditekankan guru dapat menggunakan media pembelajaran dengan baik agar mampu membangkitkan minat dan motivasi siswa. Disisi lain berdasar pada penyebaran angket analisis kebutuhan, yang diisi oleh 30 siswa kelas 
X SMA Islam Bina Insan, terkait tentang media pembelajaran yang disukai menunjukkan bahwa 28 siswa suka belajar dengan menggunakan media komputer, data tersebut menunjukkan bahwa pembelajaran berbasis komputer ini memang disukai oleh siswa. Berdasar pada masalah diatas peneliti tertarik untuk melakukan penelitian dengan judul "Pengembangan Media Pembelajaran Ekonomi Berbasis Komputer Model Drills untuk Siswa Kelas X SMA Islam Bina Insan”.

Media adalah segala sesuatu yang dapat digunakan untuk menyalurkan pesan dari pengirim ke penerima sehingga dapat merangsang pikiran, perasaan, perhatian, dan minat serta perhatian siswa sedemikian rupa sehingga proses belajar terjadi (Sadiman, 2009). Dengan pembelajaran berbasis komputer sesungguhnya dapat mempengaruhi minat dan motivasi siswa seperti hasil penelitian (Soimah, 2018) terdapat pengaruh media berbasis komputer terhadap hasil belajar IPA ditinjau dari motivasi belajar siswa kelas VII SMP Negeri 4 Gringsing Batang tahun pelajaran 2016/2017. (Halidi, Husain, \& Saehana, 2015) bahwa Penggunaan media berbasis TIK pada pembelajaran IPA berpengaruh sangat nyata terhadap motivasi dan hasil belajar IPA pada siswa Kelas V SDN Model Terpadu Madani Palu.

Disamping dapat mempengaruhi minat dan motivasi juga dapat meningkatkan kualitas pembelajaran, layak digunakan dan efektif diterapkan dalam Pembelajaran, sebagaimana hasil penelitian yang di lakukan oleh (Arda, Saehana, \& Darsikin, 2015) bahwa media pembelajaran interaktif berbasis komputer layak digunakan dan dapat meningkatkan pemahaman konsep siswa. (Febriandi, 2020) Menyimpulkan model drills berbasis komputer efektif untuk digunakan dalam pembelajaran Matematika. Selain itu penelitian yang dilakukan oleh (Jailani \& Aini, 2017) bahwa pembelajaran berbasis komputer efektif digunakan dan respon siswa terhadap pembelajaran berbasis komputer bernilai positif. Adapun penelitian (Nurlailasari \& Alkodri, 2019) dan (Kuswanto \& Ismawati, 2018) menyimpulkan bahwa Pembelajaran berbasis komputer model drills layak untuk dijadikan sebagai media bahan ajar karena mampu menyajikan materi ajar yang menarik dan menyenangkan 


\section{METODE}

Metode yang digunakan dalam penelitian ini adalah jenis penelitian dan pengembangan. (Research and Development) yakni metode penelitian yang digunakan untuk menghasilkan produk tertentu dan menguji keefektifan produk tersebut. Dalam penelitian pengembangan ini digunakan pengembangan yang berupa model prosedural. Model prosedural adalah model yang bersifat deskriptif, yaitu menunjukkan langkah-langkah yang harus diikuti untuk menghasilkan produk. Model yang digunakan dalam penelitian pengembangan ini memodifikasi model pengembangan Borg and Gall (Sugiyono \& Kuantitatif, 2009). Peneliti mengambil beberapa alternatif penelitian karena penelitian sifatnya dinamis sesuai dengan apa yang terdapat pada lapangan. Langkah-langkah pengembangan model pembelajaran yang telah disesuaikan dengan keadaan lapangan, keterbatasan waktu, tenaga dan biaya digambarkan pada gambar 1 . berikut:

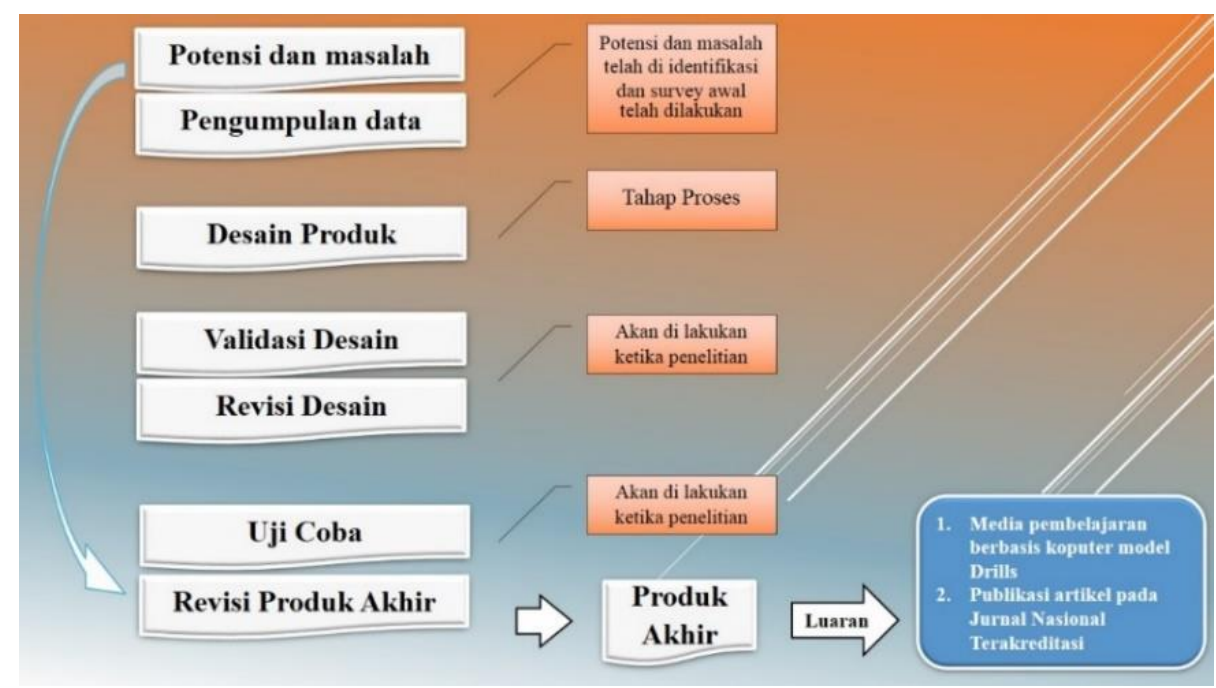

Gambar 1. Diagram Alir Rancangan pengembangan Media Pembelajaran (Adaptasi: Borg and Gall yang telah dimodifikasi)

Uji Coba Produk

Tingkat kualitas dan kemenarikan dari Media pembelajaran diketahui melalui hasil analisis kegiatan uji coba yang dilakukan dalam 2 tahap, yaitu:

- Review oleh ahli media / desain multimedia serta ahli materi oleh dosen dan guru ekonomi di sekolah 
- Uji coba lapangan terbatas yang dilakukan di sekolah

Teknik pengumpulan data dalam penelitian pengembangan ini menggunakan Angket, Tes, dan Pedoman observasi. Adapun teknik analisis data yang digunakan dalam mengelola hasil pengembangan ada dua, yaitu:

- Analisis Deskriptif Prosentase

Data yang diperoleh dari subjek uji coba (validator) dianalisis dengan teknik analisis deskriptif prosentase. Untuk menentukan kesimpulan yang telah tercapai, maka diterapkan kriteria seperti dalam tabel berikut ini.

Tabel.1 : Kriteria kelayakan

\begin{tabular}{ccl}
\hline $\begin{array}{c}\text { Kriteria Kelayakan } \\
\text { Persentase }(\%)\end{array}$ & Kriteria validasi & \multicolumn{1}{c}{ Keterangan } \\
\hline $85,01-100,00$ & Valid & Layak/Tidak perlu direvisi \\
\hline $70,01-85,00$ & Cukup valid & Cukup Layak/Tidak perlu direvisi \\
\hline $50,01-70,00$ & Kurang valid & kurang Layak / revisi sebagian \\
\hline $01,00-50,00$ & Tidak cukup valid & Tidak Layak / revisi total
\end{tabular}

- Menghitung Skor Aktivitas Belajar

Efektivitas belajar dilihat dari hasil observasi aktivitas belajar siswa dengan menghitung skor aktivitas

Skor $(x)=\frac{(n 1 \times 1)+(n 2 \times 2)+(n 3 \times 3)+(n 4 \times 4)(n 5 \times 5)}{(\text { Banyaknyaresponden }) x(\text { Banyak item })}$

\section{HASIL DAN PEMBAHASAN}

Hasil

Analisis data validasi terdiri dari analisis data ahli materi, data ahli media, dan data uji coba produk. Analisis data dilakukan pada setiap item pertanyaan dan total keseluruhan item pertanyaan. Analisis dapat dijabarkan sebagai berikut:

\section{Analisis Hasil Validasi Ahli Materi}

Data yang diperoleh berupa hasil angket tertutup yang digunakan sebagai dasar untuk menentukan kevalidan/kelayakan Media pembelajaran ekonomi berbasis komputer model Drills. Data yang diperoleh sebagai berikut: 
Tabel 1 Hasil Validasi Ahli Materi

\begin{tabular}{llccc}
\hline No & Aspek yang dinilai & $\begin{array}{c}\text { Persen } \\
\text { tase } \\
(\mathbf{\%})\end{array}$ & $\begin{array}{c}\text { Kriteria } \\
\text { Kevalid } \\
\text { an }\end{array}$ & Keterangan \\
\hline 1 & Relevansi Materi & 92 & Valid & $\begin{array}{c}\text { Layak/tidak } \\
\text { perlu direvisi }\end{array}$ \\
\hline 2 & $\begin{array}{l}\text { Pengorganisasian } \\
\text { Materi }\end{array}$ & 88 & $\begin{array}{c}\text { Cukup } \\
\text { Valid }\end{array}$ & $\begin{array}{c}\text { Layak/tidak } \\
\text { perlu direvisi }\end{array}$ \\
\hline 3 & Bahasa & 90 & valid & $\begin{array}{c}\text { Layak/tidak } \\
\text { perlu direvisi }\end{array}$ \\
\hline Rata-rata & $\mathbf{8 9 , 0 9}$ & Valid & $\begin{array}{c}\text { Layak/tidak } \\
\text { perlu direvisi }\end{array}$ \\
\hline
\end{tabular}

Berdasarkan tabel 1 dapat dilihat bahwasannya penilaian dari ahli materi pada aspek relevansi materi diperoleh kriteria Valid dan dapat digunakan dengan persentase sebesar 92\%, pada aspek pengorganisasian materi diperoleh kriteria cukup valid dan dapat digunakan dengan persentase $88 \%$, selanjutnya pada aspek bahasa diperoleh kriteria valid dan dapat digunakan dengan presetasi 90\%. Hasil validasi Media pembelajaran ekonomi berbasis koputer dengan model Drills dari ahli materi diperoleh nilai rata-rata persentase sebesar 89,09\%. Dari beberapa data ini dapat disimpulkan bahwasannya Media pembelajaran ekonomi berbasis komputer model Drills yang dikembangkan peneliti valid dan dapat digunakan dari segi materi pada siswa kelas X SMA Islam Bina Insan.

\section{Analisis Hasil Validasi Ahli Media}

Data yang diperoleh dari validasi Media disajikan sebagai berikut:

Tabel 2. Hasil Validasi Media

\begin{tabular}{llccc}
\hline No & Aspek yang dinilai & $\begin{array}{c}\text { Persen } \\
\text { tase } \\
(\mathbf{\%})\end{array}$ & $\begin{array}{c}\text { Kriteria } \\
\text { Kevalid } \\
\text { an }\end{array}$ & Keterangan \\
\hline 1 & Aspek Bahasa & 93,33 & Valid & $\begin{array}{c}\text { Layak/tidak } \\
\text { perlu direvisi }\end{array}$ \\
\hline 2 & Aspek Tampilan & 90 & $\begin{array}{c}\text { Cukup } \\
\text { Valid }\end{array}$ & $\begin{array}{c}\text { Layak/tidak } \\
\text { perlu direvisi }\end{array}$ \\
\hline 3 & $\begin{array}{l}\text { Aspek Penggunaan } \\
\text { Software / Aplikasi }\end{array}$ & 95 & valid & $\begin{array}{c}\text { Layak/tidak } \\
\text { perlu direvisi }\end{array}$ \\
\hline Rata-rata & $\mathbf{9 2 , 3 0}$ & Valid & $\begin{array}{c}\text { Layak/tidak } \\
\text { perlu direvisi }\end{array}$ \\
\hline
\end{tabular}


Berdasarkan tabel 2 Analisis Validasi Ahli Media dapat dilihat hasil analisis terhadap angket validasi oleh ahli Media dari aspek bahasa diperoleh kriteria valid dan dapat digunakan dengan persentase sebesar 93,33\%, selanjutnya pada Aspek Tampilan diperoleh kriteria valid dan dapat digunakan dengan persentase 90\%., dan untuk aspek penggunaan software/aplikasi diperoleh kriteria valid dan dapat digunakan dengan persentase sebesar $95 \%$. Hasil validasi Media pembelajaran Ekonomi berbasis komputer dengan model Drills dari ahli media diperoleh rata-rata persentase keseluruhan sebesar 92,30\% maka pengembangan Media pembelajaran ekonomi berbasis komputer pada pokok bahasan perilaku konsumen dan produsen dalam kegiatan ekonomi yang telah dikembangkan dinyatakan valid dan layak digunakan dalam proses pembelajaran ekonomi kelas X di SMA Islam Bina Insan.

\section{Hasil Uji Coba Produk}

Uji coba produk (siswa) dilakukan setelah adanya proses validasi dari ahli materi dan ahli media. Uji coba ini dilakukan untuk melihat a). tanggapan/respon siswa b), tanggapan/respon guru, c).Melihat efektivitas belajar siswa, Data uji coba produk dilakukan peneliti dengan mengambil sampel di SMA Islam Bina Insan Sejumlah 25 siswa kelas X IPS. Berikut hasil pengumpulan data dari uji coba produk

a. Analisis Respon atau Tanggapan Siswa Ekonomi Kelas X SMA ISLAM Bina Insan

Analisis respon atau tanggapan siswa terhadap Media pembelajaran ekonomi berbasis komputer model Drills dijelaskan dalam tabel berikut:

Tabel 3. Rekapitulasi Hasil Angket Respon Atau Tanggapan Siswa

\begin{tabular}{lllcc}
\hline No & \multicolumn{1}{c}{ Deskripsi } & \multicolumn{2}{c}{ Penilaian } \\
\cline { 3 - 5 } & & $\sum \mathbf{X i}$ & $\sum \mathbf{Y i}$ & $\mathbf{\%}$ \\
\hline 1 & Tujuan Pembelajaran sangat jelas & 116 & 125 & 92,8 \\
\hline 2 & $\begin{array}{l}\text { Media pembelajaran ekonomi berbasis komputer model Drills } \\
\text { membantu siswa memahami isi materi ajar }\end{array}$ & 111 & 125 & 88,8 \\
\hline 3 & $\begin{array}{l}\text { Paparan Materi dalam Media pembelajaran Ekonomi berbasis } \\
\text { komputer dengan model Drills ini sangat jelas }\end{array}$ & 114 & 125 & 91,2 \\
\hline
\end{tabular}




\begin{tabular}{llccc}
\hline 4 & $\begin{array}{l}\text { Media pembelajaran Ekonomi berbasis komputer dengan } \\
\text { model Drills menambah pengetahuan dan wawasan siswa } \\
\text { tentang ekonomi utamanya pada pokok bahasan perilaku } \\
\text { konsumen dan produsen dalam kegiatan ekonomi }\end{array}$ & 113 & 125 & 90,4 \\
\hline 5 & $\begin{array}{l}\text { Media pembelajaran Ekonomi berbasis komputer dengan } \\
\text { model Drills dapat meningkatkan keaktifan siswa dalam } \\
\text { pembelajaran }\end{array}$ & 113 & 125 & 90,4 \\
\hline 6 & $\begin{array}{l}\text { Saya merasa senang dan tertarik dengan pelajaran ekonomi } \\
\text { yang dikaitkan dengan kehidupan nyata dengan Tugas mandiri } \\
\text { dan kelompok sesuai dengan kondisi wilayah masing-masing } \\
\text { siswa }\end{array}$ & 113 & 125 & 90,4 \\
\hline 7 & $\begin{array}{l}\text { Media pembelajaran ekonomi berbasis komputer dengan model } \\
\text { Drills memberi kemudahan dalam belajar dan terjadi interaksi } \\
\text { positif antara sesama teman dengan guru }\end{array}$ & 108 & 125 & 86,4 \\
\hline 8 & $\begin{array}{l}\text { Media pembelajaran Ekonomi berbasis komputer dengan } \\
\text { model Drills membuat siswa termotivasi untuk belajar } \\
\text { Ekonomi }\end{array}$ & 114 & 125 & 91,2 \\
\hline 9 & $\begin{array}{l}\text { Media pembelajaran Ekonomi berbasis komputer dengan } \\
\text { model Drills dapat meningkatkan wawasan siswa tentang } \\
\text { Perilaku konsumen dan produsen dalam kegiatan ekonomi }\end{array}$ & 110 & 125 & 88 \\
\hline 10 & $\begin{array}{l}\text { Dengan digunakannya Media pembelajaran Ekonomi berbasis } \\
\text { komputer dengan model Drills membuat siswa lebih } \\
\text { memahami praktek yang terjadi di lapangan terkait tentang } \\
\text { Perilaku konsumen dan produsen dalam kegiatan ekonomi }\end{array}$ & 108 & 125 & 86,4 \\
\hline & Skor rata-rata & $\mathbf{1 1 2 0}$ & $\mathbf{1 2 5 0}$ & $\mathbf{8 9 , 6}$ \\
\hline
\end{tabular}

Dari tabel 3 diatas, diperoleh data mengenai angket respon siswa..

dimana dari hasil angket yang diperoleh dari 25 siswa bahwasannya didapatkan skor rata-rata sebanyak $89,6 \%$ ini artinya dari segi kelayakan Media pembelajaran kategorinya sudah valid dan tentunya hal ini mengindikasikan bahwa siswa memberikan respon positif terhadap Media pembelajaran ekonomi berbasis komputer dengan model Drills pada pokok bahasan perilaku konsumen dan produsen dalam kegiatan ekonomi di SMA Islam Bina Insan

b. Analisis Respoon atau Tanggapan Guru Ekonomi Kelas X SMA ISLAM Bina Insan

Berikut hasil angket yang telah di isi oleh guru bidang studi pendidikan ekonomi yang dalam hal ini adalah Hilmi Zinnuraini, S.Pd 
Tabel 4. Rekapitulasi Hasil Angket Respon Atau Tanggapan Guru

\begin{tabular}{|c|c|c|c|}
\hline \multirow{2}{*}{ Pernyataan } & \multicolumn{3}{|c|}{ Penilaian presen } \\
\hline & $\sum \mathbf{X i}$ & $\sum \mathbf{Y i}$ & tase \\
\hline $\begin{array}{l}\text { Kesesuaian model yang dikembangkan dengan tujuan } \\
\text { 1. pembelajaran }\end{array}$ & 1 & 1 & 100 \\
\hline $\begin{array}{l}\text { Kesesuaian antara model pembelajaran dan Media pembelajaran } \\
\text { 2. ekonomi berbasis komputer }\end{array}$ & 1 & 1 & 100 \\
\hline $\begin{array}{l}\text { Kesesuaian Media pembelajaran ekonomi berbasis komputer } \\
\text { 3. model Drills dengan kemampuan guru dan siswa }\end{array}$ & 1 & 1 & 100 \\
\hline $\begin{array}{l}\text { Kesesuaian Media pembelajaran ekonomi berbasis komputer } \\
\text { 4. model Drills dengan obyek kunjungan siswa dalam proses }\end{array}$ & 1 & 1 & 100 \\
\hline $\begin{array}{l}\text { Kesesuaian Media pembelajaran yang interdisipliner keilmuan } \\
\text { dalam lingkup bidang ekonomi }\end{array}$ & 1 & 1 & 100 \\
\hline 6. Kesesuaian skenario pembelajaran dengan materi ajar & 1 & 1 & 100 \\
\hline $\begin{array}{l}\text { Kesesuaian alokasi waktu dengan model pembelajaran dan } \\
\text { 7. Media pembelajaran yang akan dilaksanakan }\end{array}$ & 1 & 1 & 100 \\
\hline $\begin{array}{l}\text { Kesesuaian Media pembelajaran ekonomi berbasis komputer } \\
\text { 8. model Drills dengan latihan dan praktek siswa }\end{array}$ & 1 & 1 & 100 \\
\hline $\begin{array}{l}\text { Kesesuaian Media pembelajaran ekonomi berbasis komputer } \\
\text { model Drills dengan media pembelajaran }\end{array}$ & 1 & 1 & 100 \\
\hline $\begin{array}{l}\text { Kesesuaian Media pembelajaran ekonomi berbasis komputer } \\
10 \text { model Drills dengan kebutuhan siswa }\end{array}$ & 1 & 1 & 100 \\
\hline Skor Rata-rata & 10 & 10 & $100 \%$ \\
\hline
\end{tabular}

Dari tabel 4 diatas, diperoleh data mengenai angket respon guru..

dimana dari hasil angket yang diperoleh dari satu guru bidang studi pendidikan ekonomi bahwasannya didapatkan skor rata-rata sebanyak $100 \%$ ini artinya dari segi kelayakan Media pembelajaran kategorinya sudah valid dan tentunya hal ini mengindikasikan bahwa guru bidang studi pendidikan ekonomi memberikan respon positif terhadap Media pembelajaran ekonomi berbasis komputer dengan model Drills pada pokok bahasan perilaku konsumen dan produsen dalam kegiatan ekonomi di SMA Islam Bina Insan.

\section{c. Analisis Data Keefektifan Media Pembelajaran Berbasis Komputer Dengan Model Drills}

Data tentang keefektifan Media pembelajaran ekonomi bebasis komputer dengan model Drills ini dilihat dari data hasil observasi yang telah 
dilakukan peneliti melalui lembar pedoman observasi. Berikut dijelaskan data tersebut saat dilakukan uji coba produk.

Tabel 5 Data Ringkasan Hasil Observasi

\begin{tabular}{clc}
\hline No & \multicolumn{1}{c}{ Indikator } & Skor \\
\hline 1 & $\begin{array}{l}\text { Kesiapan siswa dalam mengikuti kegiatan } \\
\text { pembelajaran }\end{array}$ & 4,40 \\
\hline 2 & Antusiasme siswa dalam mengikuti pembelajaran & 3,96 \\
\hline 3 & Intraksi siswa dengan siswa & 3,96 \\
\hline 4 & Intraksi siswa dengan guru & 3,92 \\
\hline 5 & Kerjasama dalam kelompok & 3,80 \\
\hline 6 & Aktivitas siswa dalam diskusi kelompok & 3,72 \\
\hline 7 & Aktivitas siswa dalam pembelajaran & 3,88 \\
\hline 8 & Partisipasi siswa dalam menyimpulkan hasil belajar & 3,60 \\
\hline Jumlah skor aktivitas & 31.24 \\
\hline Rata-rata skor aktivitas & Aktif \\
\hline Kategori & Berdasarkan data hasil observasi tersebut diatas bahwasannya uji \\
\hline \multicolumn{3}{l}{ coba produk Media pembelajaran ekonomi berbasis komputer model Drills } \\
efektif digunakan, dimana hal tersebut ditunjukkan dari aktivitas belajar \\
siswa yang terkategori aktif dengan rata-rata skor aktivitas sebanyak 3,9. \\
Dengan aktifnya suasana belajar dikelas mengindikasikan bahwa Media \\
pembelajaran efektif digunakan
\end{tabular}

Pembahasan

Dari beberapa kegiatan yang telah dilakukan, data yang didapat memiliki nilai yang positif sehingga media pembelajaran yang digunakan dapat di terapkan disekolah oleh guru bidang studi ekonomi atau lainnya, karena beberapa penelitan yang relevan menjelaskan pembelajaran berbasis komputer ini memang dapat meningkatkan aktivitas belajar siswa, dapat meningkatkan minat dan motivasi siswa yang tentunya bermuara pada hasil belajar siswa, sebagaimana beberapa penelitian yang telah dilakukan oleh (Jailani \& Aini, 2017) bahwa pembelajaran berbasis komputer efektif digunakan dan respon siswa terhadap pembelajaran berbasis komputer bernilai positif. Saat penelitian di SMA Islam Bina Insani ini berlangsung 
siswa tampak termotivasi belajarnya karena diberikan suasana yang berbeda dalam pola pembelajarannya hal ini senada dengan penelitian yang dilakukan oleh penelitian (Dewi \& Nugroho, 2015) bahwa media pembelajaran dapat meningkatkan motivasi bahkan keterampilan memprediksi siswa. Disamping dapat mempengaruhi minat dan motivasi juga dapat meningkatkan kualitas pembelajaran, layak digunakan dan efektif diterapkan dalam Pembelajaran, sebagaimana hasil penelitian yang di lakukan oleh (Arda et al., 2015) bahwa media pembelajaran interaktif berbasis komputer layak digunakan dan dapat meningkatkan pemahaman konsep siswa. (Febriandi, 2020) Menyimpulkan model drills berbasis komputer efektif untuk digunakan dalam pembelajaran Matematika

\section{KESIMPULAN}

Kesimpulan dari penelitian ini adalah 1). Adanya produk berupa Media Pembelajaran ekonomi berbasis komputer model Drills Untuk SMA Islam Bina Insan. 2). Media pembelajaran ekonomi berbasis komputer model Drills ini layak digunakan, hal tersebut dapat dilihat dari hasil validasi ahli materi ekonomi sebesar $89,09 \%$ (layak), untuk ahli media sebesar 92,30\% (layak). 3). Respon guru dan siswa menunjukkan respon yang positif dilihat dari hasil uji coba lapangan yakni hasil angket respon guru sebesari $100 \%$ dan respon siswa sebesar $89,6 \%$. 4).Untuk hasil aktifitas belajar siswa sebesar 3,7 dengan demikian Media Pembelajaran ekonomi berbasis komputer model Driils ini efektif digunakan

\section{DAFTAR RUJUKAN}

Arda, A., Saehana, S., \& Darsikin, D. (2015). Pengembangan media pembelajaran interaktif berbasis komputer untuk siswa SMP Kelas VIII. Mitra Sains, 3(1), 69-77.

Dewi, R. A. K., \& Nugroho, S. E. (2015). Pengaruh media computer based instruction (CBI) berorientasi POE dalam meningkatkan motivasi dan keterampilan memprediksi IPA siswa kelas IV. Journal of Primary Education, $4(2), 139-146$.

Febriandi, R. (2020). Penerapan Model Drills Dalam Pembelajaran Matematika Berbasis Komputer Pada Siswa Kelas Xi Ipa Man 1 Lubuklinggau. Journal of 
Mathematics Science and Education, 2(2), 80-95.

Halidi, H. M., Husain, S. N., \& Saehana, S. (2015). Pengaruh Media Pembelajaran Berbasis TIK Terhadap Motivasi dan Hasil Belajar IPA Siswa Kelas V SDN Model Terpadu Madani Palu. Mitra Sains, 3(1), 53-60.

Jailani, H., \& Aini, Q. (2017). Pengembangan Bahan Ajar Ekonomi Berbasis Komputer dengan Model Tutorial Pada Pokok Bahasan Uang dan Perbankan Untuk Siswa Kelas X MA Mu'allimin Nw Pancor. Jurnal Pendidikan Ekonomi Dan Kewirausahaan, 1(2), 68-81.

Kuswanto, J., \& Ismawati, I. (2018). Pengembangan Media Pembelajaran Berbasis Komputer Model Drill pada Mata Pelajaran PKN Kelas X. Teknomatika, 8(1).

Nurlailasari, P. A., \& Alkodri, M. N. (2019). Pengembangan Media Pembelajaran Berbasis Komputer Model Drill Pada Mata Pelajaran Fiqih. BaJET (Baturaja Journal of Education Technology), 3(2), 194-199.

Sadiman, A. S. (2009). Media Pendidikan: Pengertian dan Pemanfaatannya Edisi 1 Cetakan Ke-13. Jakarta: Raja Grafindo Persada.

Serin, O. (2011). The Effects of the Computer-Based Instruction on the Achievement and Problem Solving Skills of the Science and Technology Students. Turkish Online Journal of Educational Technology-TOJET, 10(1), 183-201.

Soimah, I. (2018). Pengaruh media pembelajaran berbasis komputer terhadap hasil belajar IPA ditinjau dari motivasi belajar siswa. Natural: Jurnal Ilmiah Pendidikan IPA, 5(1), 38-44.

Sugiyono, M. P. P., \& Kuantitatif, P. (2009). Kualitatif, dan R\&D, Bandung: Alfabeta. Cet. VII. 